\title{
A Case of 45-Year Man Who Succumbed to Coronavirus Disease 2019 (COVID-19)
}

\author{
Muhammad Ahmed Khan and Muhammad Ameen Khan \\ Combined Military Hospital, Mardan, Pakistan
}

\begin{abstract}
We present a case of a 45-year male with history of fever and cough, followed by shortness of breath, lethargy and confusion at home. He was a known hypertensive, smoker and naswaar addict. He had history of contact with a friend who had recently returned from China, and used to work there as a physician. On presentation, he was hypoxic with bilateral coarse crepitations; and chest radiograph showed left middle zone consolidation. Considering the current pandemic, provisional diagnosis of meningoencephilits, with bilateral pneumonia owing to COVID-19, was made. Throat swab was sent for COVID-19 polymerase chain reaction (PCR). He was managed in intensive care unit (ICU) with broad-spectrum antibiotics, hydroxychloroquine alongwith anticoagulants; but he remained hypoxic with rapidly worsening clinical course, requiring mechanical ventilation; and ultimately succumbed to the disease. Report of COVID-19 PCR came positive after 24 hours.
\end{abstract}

Key words: Coronavirus disease 2019 (COVID-19), Meningoencephalitis, Pneumonia.

How to cite this article: Khan MA, Khan MA. A Case of 45-Year Man Who Succumbed to Coronavirus Disease 2019 (COVID-19). J Coll Physicians Surg Pak 2020; 30(JCPSPCR):CR37-CR39 https://doi.org/10.29271/jcpsp.2020.JCPSPCR.CR37.

\section{INTRODUCTION}

Coronaviruses belong to the order nidovirales and family coronaviridae. The emergence of novel corona viruses resulted from mutations leading to crossing from animals to human. The epidemics in the past due to severe acute respiratory syndrome coronavirus (SARS CoV-1) and Middle-east respiratory syndrome (MERS CoV-1) caused serious illness in humans. ${ }^{1}$ In December 2019, a cluster of patients with pneumonia of unknown etiology was identified in Hubei province of China. Testing of respiratory specimen from those patients established severe acute respiratory syndrome coronavirus 2 (SARS CoV-2) as the underlying pathogen, initially labelled as novel coronavirus; and the disease has been named coronavirus disease 2019 (COVID-19). These individuals worked in a seafood market suggesting a zoonotic source of infection. The mode of transmission for SARS CoV-2 is via droplets and direct contact through fomites from symptomatic and presymptomatic individuals. The clinical symptoms are somewhat similar to SARS which include fever, dry cough, myalgias, shortness of breath, sore throat, and lethargy. Other less common symptoms include flu, stuffy nose, diarrhoea, vomiting, headache, etc. $^{2}$

Correspondence to: Dr. Muhammad Ahmed Khan,

Combined Military Hospital, Mardan, Pakistan

E-mail: akawan79@gmail.com

Received: April 02, 2020; Revised: April 14, 2020;

Accepted: April 15, 2020

DOI: https://doi.org/10.29271/jcpsp.2020.JCPSPCR.CR37
Suggestive laboratory findings include leukopenia, leucocytosis, lymphopenia, raised lactate dehydrogenase (LDH), and ferritin levels; while the diagnostic test is PCR of the respiratory secretions, including nasopharyngeal or oropharyngeal swabs and sputum. The commonly observed radiographic findings so far include ground glass opacities and bilateral pulmonary infiltrates. ${ }^{3}$ Social distancing, regular hand washing, and isolation have proven to reduce the spread of the infection. ${ }^{4,5}$ There is no promising cure or vaccination for this viral illness at present; but various trials are underway worldwide to assess efficacy of various drugs for COVID-19 including chloroquine, hydroxychloroquine, azithromycin, remdesivir, and lopinavir/ritonavir. ${ }^{6,7}$

We, herein present a case of a 45 -year male who died of COVID-19, despite all above measures and mechanical ventilation; and describe its clinical, laboratory and radiological features to increase the awareness of medical community.

\section{CASE REPORT}

A 45-year male, resident of Madyan, Bahrain, got admitted to Saidu Sharif Hospital with 3 days' history of fever and cough, followed by shortness of breath, weakness and confusion. Underlying comorbid conditions included hypertension, for which he was on iosartan $50 \mathrm{mg}$ once a day with poor compliance. He was a known smoker and naswaar addict. He had history of recent contact with a friend who returned from China, and worked there as a physician. Despite treatment, his condition deteriorated, so he was referred to $\mathrm{CMH}$, Mardan. He was hypoxic on presentation to emergency unit with oxygen saturation of $72 \%$ at room air, heart rate of 92 beats/minute, 
blood pressure of 100/60 $\mathrm{mmHg}$ and Glasgo coma scale (GCS) score of 10/15. Chest examination revealed bilateral coarse crepitations. He was admitted to intensive care unit (ICU) for further management. Initial investigations revealed total leucocyte count $24.2 \times 10^{3} / \mathrm{uL}^{\prime}$ with lymphocytes $1.2 \times 10^{3} / \mathrm{uL}^{\prime}$, neutrophil count $21.2 \times 10^{3} / \mathrm{uL}$, alanine transaminase $44 \mathrm{IU} / \mathrm{L}$, serum urea $12.8 \mathrm{mmol} / \mathrm{L}$, serum creatinine $160 \mu \mathrm{mol} / \mathrm{L}$, and elevated D-dimers ( $749 \mathrm{ng} / \mathrm{mL}$ ), as shown in Table I. Chest X-ray showed consolidation in left middle zone with blunting of left costophrenic angle and right lower lung opacities as shown in Figure 1.

Table I: Investigations.

\begin{tabular}{|l|l|l|}
\hline Investigation & Value & Normal value \\
\hline Hemoglobin & $15.2 \mathrm{~g} / \mathrm{dL}$ & $12-18 \mathrm{~g} / \mathrm{dL}$ \\
\hline $\begin{array}{l}\text { White blood cell } \\
\text { count }\end{array}$ & $24.2 \times 10^{3} / \mathrm{uL}$ & $4-11 \times 10^{3} / \mathrm{uL}$ \\
\hline Neutrophil count & $\begin{array}{l}21.2 \times 10^{3} / \mathrm{uL} \\
(87.7 \%)\end{array}$ & $\begin{array}{l}1.8-8 \times 10^{3} / \mathrm{uL} \\
(40-75 \%)\end{array}$ \\
\hline Lymphocyte count & $1.2 \times 10^{3} / \mathrm{uL}(5.1 \%)$ & $\begin{array}{l}0.8-5 \times 10^{3} / \mathrm{uL} \\
(20-45 \%)\end{array}$ \\
\hline Monocytes count & $1.7 \times 10^{3} / \mathrm{uL}(7.2 \%)$ & $\begin{array}{l}10.4-1 \times 10^{3} / \mathrm{uL} \\
(2-10 \%)\end{array}$ \\
\hline Platelets count & $225 \times 10^{3} / \mathrm{uL}$ & $150-400 \times 10^{3} / \mathrm{uL}$ \\
\hline PT & $20 \mathrm{~seconds}$ & $14 \mathrm{~seconds}$ \\
\hline PTTK & $38 \mathrm{~seconds}$ & $34 \mathrm{~seconds}$ \\
\hline Bilirubin level & $14 \mathrm{umol} / \mathrm{L}$ & $<18 \mathrm{umol} / \mathrm{L}$ \\
\hline ALT & $44 \mathrm{IU} / \mathrm{L}$ & $<42 \mathrm{IU} / \mathrm{L}$ \\
\hline ALP & $959 \mathrm{IU} / \mathrm{L}$ & Adult $<275 \mathrm{IU} / \mathrm{L}$ \\
\hline S. urea & $12.8 \mathrm{mmol} / \mathrm{L}$ & $3.3-8.7 \mathrm{mmol} / \mathrm{L}$ \\
\hline S. creatinine & $160 \mathrm{umol} / \mathrm{L}$ & $53-115 \mathrm{umol} / \mathrm{L}$ \\
\hline D-dimers & $749 \mathrm{ng} / \mathrm{mL}$ & $<200 \mathrm{ng} / \mathrm{mL}$ \\
\hline
\end{tabular}

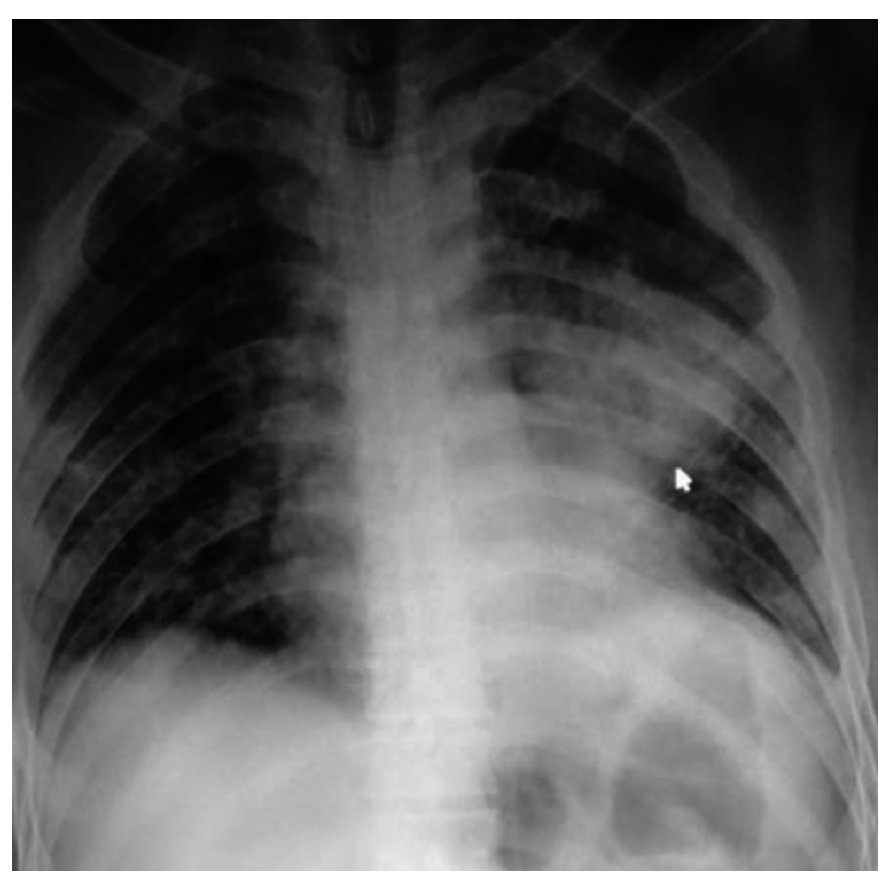

Figure 1: Chest radiograph of the patient.
Considering the current pandemic situation of COVID-19, provisional diagnosis of meningoencephilits with bilateral pneumonia due to COVID-19 was made. Oropharyngeal swab was sent for COVID-19 PCR, which turned out positive. He was managed with supplemental oxygen, IV meropenem 500 mg 8 hourly, oral azithromycin 500 mg once daily, hydroxychloroquine $400 \mathrm{mg}$ stat, followed by $200 \mathrm{mg} 12$ hourly along with enoxaparin $40 \mathrm{mg}$ subcutaneously once daily. Nasogastric tube and Foley's catheter were passed. The clinical course rapidly deteriorated with persistent hypoxia, decline in GCS to 7/15; and so the patient was put on mechanical ventilation with acute respiratory distress syndrome (ARDS) protocol. Within 24 hours, patient went into cardiac arrest and could not be revived.

\section{DISCUSSION}

As of today, i.e., 29 March 2020, there are 634,835 confirmed cases of COVID-19, with 299,957 deaths worldwide. ${ }^{8}$ This virus affects all age groups but has serious implications in individuals at the extremes of age, i.e., old patients who are suffering from chronic diseases previously, such as cardiovascular conditions, diabetics, stroke and cancer patients on chemotherapy. ${ }^{7,9}$ It runs a different course in every patient depending upon the immune status; and it has been concluded that people with low immunity are more likely to suffer from extreme complications including death. ${ }^{2}$ In USA, more than $80 \%$ deaths have occurred in cases who were older than 65 years. ${ }^{9}$ Similarly, in China, more than $80 \%$ deaths occurred in individuals older than 60 years. ${ }^{10}$ It is not easy to diagnose a case of COVID-19 because of associated symptoms. A detailed and thorough history (especially of contact with any affected individual or any person who has travelled from a place or region where he might have acquired COVID-19 and is in asymptomatic or incubation phase) is vital. The risk of death from COVID-19 in China was reported to be as high as $12 \%$ in epicentre of epidemic, and $1 \%$ in less affected regions of China at the same time. ${ }^{10}$

As there is no promising therapeutic remedy or vaccination currently available, so public health interventions including social distancing, hygienic measures, and infection control should be adopted. ${ }^{4-7}$

In summary, this case highlights the need to consider COVID-19 in the differential diagnosis of all cases of community-acquired pneuomia, especially in those with a relevant contact or travel history.

\section{PATIENT' CONSENT:}

Consents from attendants were obtained before publishing data regarding this case.

\section{CONFLICT OF INTEREST:}

Authors declared no conflict of interest.

\section{AUTHORS' CONTRIBUTION:}

$\operatorname{MAK}\left(1^{\text {st }}\right.$ author): Received the patient in Emergency Department, collected data and wrote the case report.

MAK ( $2^{\text {nd }}$ author): Managed the patient in COVID ICU Department. 


\section{REFERENCES}

1. Chan JFP, Lau SKP, To KKW, Cheng VC, Woo PCY, Yuen KY. Middle-east respiratory syndrome coronavirus: Another zoonotic beta coronavirus causing sars-like disease. Clin Microbiol Rev 2015; 28(2):465-522.

2. Guo YR, Cao QD, Hong ZS, Tan YY, Chen SD, Jin HJ, Ten KS, et al. The origin, transmission and clinical therapies on coronavirus disease 2019 (COVID-19) - an update on the status. Mil Med Res 2020; 7(1):11.

3. Zowalaty MEE, Jarhult JD. From SARS to COVID-19: A previously unknown SARS-related coronavirus (SARS-CoV2) of pandemic potential infecting human - Call for a onehealth approach. One Health 2020; 9:100124.

4. Riou J, Althaus CL. Pattern of early human to human transmission of Wuhan 2019 novel coronavirus (2019nCoV), December 2019 to January 2020. Euro Surveill 2020; 25(4):2000058.

5. Prem K, Liu Y, Russell TW, Kucharski AJ, Eggo RM, Davies N, et al. The effect of control strategies to reduce social mixing on outcome of the COVID-19 epidemic in Wuhan,
China: A modelling study. Lancet Public Health 2020; 5(5):e261-71.

6. Cennimo DJ. Coronavirus disease 2019 (COVID-19) treatment and management. Medscape 2020.

7. Kakodkar P, Kaka N, Baig MN. A comprehensive literature review on the clinical presentation, and management of the pandemic coronavirus disease (COVID-19). Cereus 2020; 12(4):e7560.

8. World Health Organization. Coronavirus disease 2019 (COVID-19) situation report - 69. http://www.who.int. Accessed on 29 March 2020.

9. Centre for disease control and prevention. Mortality and morbidity weekly report (MMWR). Severe outcomes among patients with coronavirus disease 2019 (COVID-19) - United States, Februray 12-16 March, 2020. Weekly 2020; 12: 343-6.

10. Novel coronavirus pneumonia emerging response epidemiology team. The epidemiological characteristics of of an outbreak of 2019 novel coronavirus disease (COVID-19) in China. Chinese centre for disease control and prevention, Weekly 2020; 41:145-51. 